
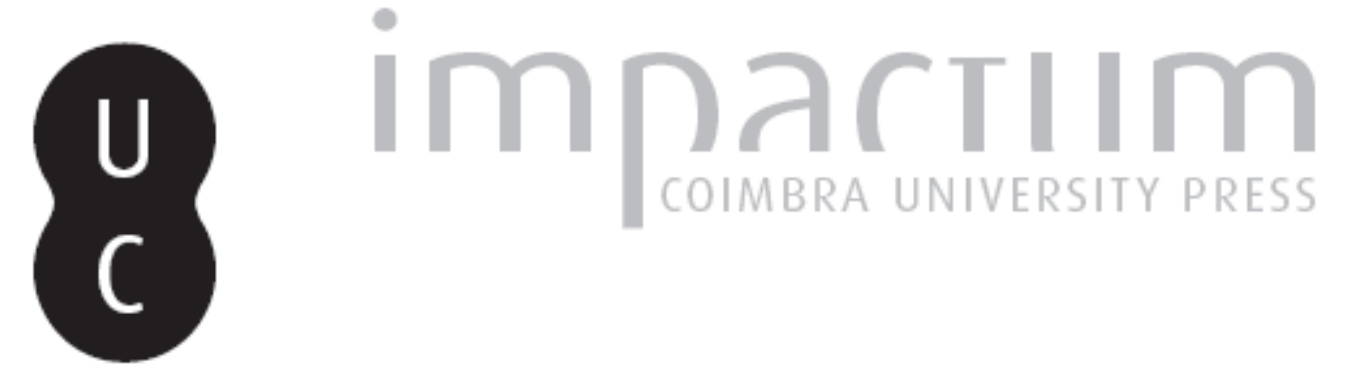

\title{
El turno de los campesinos: protesta social en la España rural del cambio de siglo (1898-1923)
}

\author{
Autor(es): Redondo Cardeñoso, Jesús-Ángel \\ Publicado por: Centro de História da Sociedade e da Cultura \\ URL \\ persistente: \\ URI:http://hdl.handle.net/10316.2/39438 \\ DOI: \\ DOI:http://dx.doi.org/10.14195/1645-2259_12_17
}

Accessed : $\quad$ 26-Apr-2023 16:11:12

A navegação consulta e descarregamento dos títulos inseridos nas Bibliotecas Digitais UC Digitalis, UC Pombalina e UC Impactum, pressupõem a aceitação plena e sem reservas dos Termos e Condições de Uso destas Bibliotecas Digitais, disponíveis em https://digitalis.uc.pt/pt-pt/termos.

Conforme exposto nos referidos Termos e Condições de Uso, o descarregamento de títulos de acesso restrito requer uma licença válida de autorização devendo o utilizador aceder ao(s) documento(s) a partir de um endereço de IP da instituição detentora da supramencionada licença.

Ao utilizador é apenas permitido o descarregamento para uso pessoal, pelo que o emprego do(s) título(s) descarregado(s) para outro fim, designadamente comercial, carece de autorização do respetivo autor ou editor da obra.

Na medida em que todas as obras da UC Digitalis se encontram protegidas pelo Código do Direito de Autor e Direitos Conexos e demais legislação aplicável, toda a cópia, parcial ou total, deste documento, nos casos em que é legalmente admitida, deverá conter ou fazer-se acompanhar por este aviso.

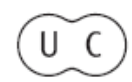


evista de História da Sociedade e da Cultura

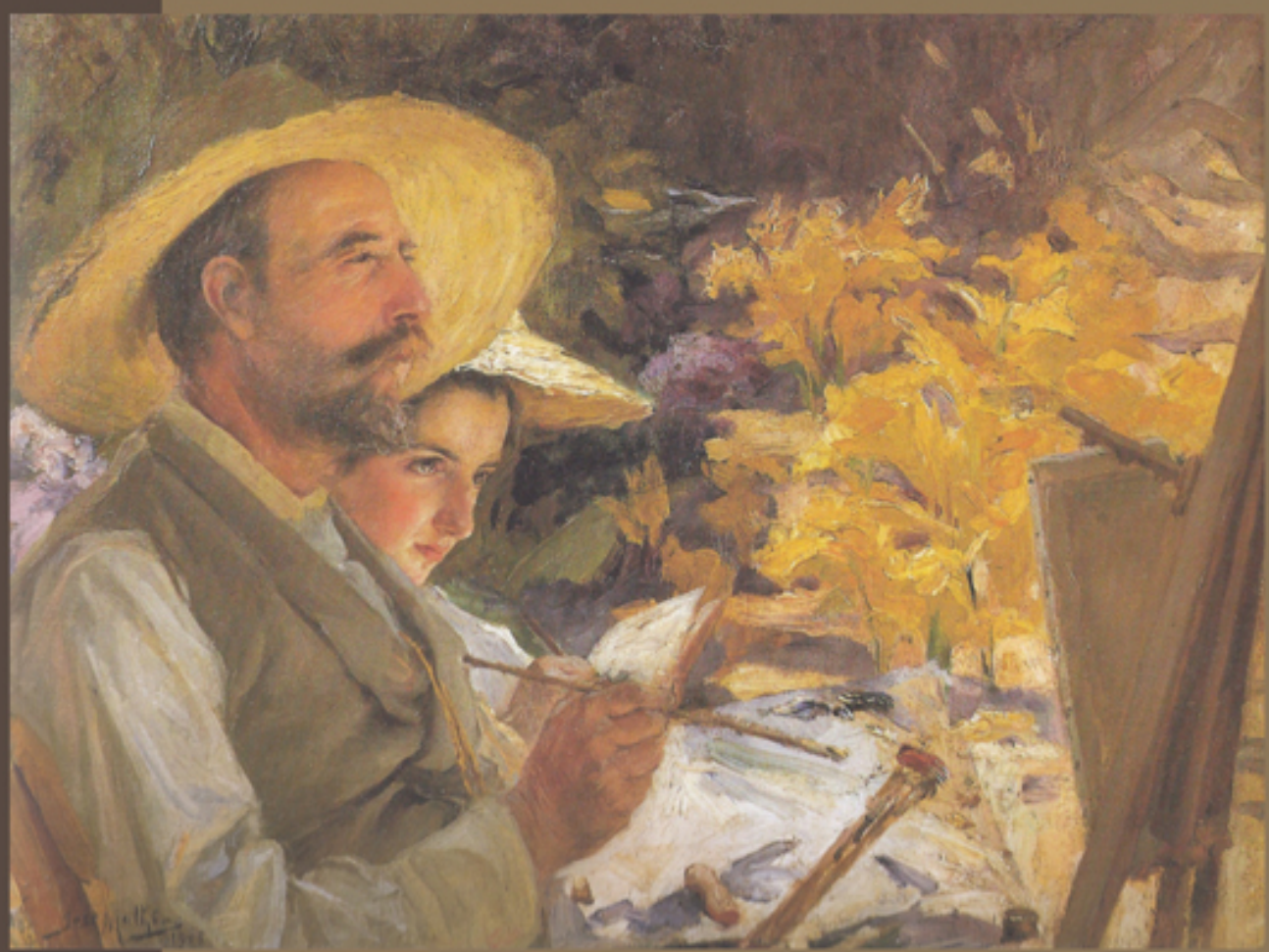

Centro de História da Sociedade e da Cultura Universidade de Coimbra 


\title{
El turno de los campesinos: protesta social en la España rural del cambio de siglo (1898-1923)
}

\author{
Jesús-Ángel Redondo Cardeñoso \\ Universidad de Valladolid, España \\ jredondocardenoso@gmail.com \\ Texto recebido em /Text submitted on: 02/01/2012 \\ Texto aprovado em /Text approved on: 10/01/2012
}

\section{Resumo/Abstract:}

En el siguiente artículo atenderemos, en primer lugar, a la evolución de la investigación historiográfica sobre el estudio de la conflictividad campesina, centrándonos en el importante salto que han dado dichos estudios en las últimas dos décadas, lo cual ha permitido transformar radicalmente la imagen histórica que sobre el campesinado ha dominado hasta hace poco tiempo. En segundo lugar, afrontaremos un análisis de los principales hitos de esa conflictividad, es decir, las acciones colectivas protagonizadas por los campesinos españoles durante los primeros años del siglo XX. Ello nos permitirá comprender la importancia del asociacionismo campesino en la consolidación del movimiento obrero español durante aquellos años y la contribución decidida de la conflictividad campesina en el desarrollo de la crisis que desmanteló el sistema político de la Restauración.

In the next paper, we pay to attention, first, to the evolution of the historiographical research about the studies of the Spanish peasant disputes in the earlier 20th century, essentially, the significant advance that these researches have received in the last two decades. It has allowed to change the historic traditional image of the Spanish peasants. Second, we deal with the main landmarks of that social disputes, specifically to the colective actions that were led by the Spanish peasants during that years. It lets us understand the importance of peasant associations in the consolidation of Spanish labor movement and the significant contribution of the peasant conflicts in the crisis of the politic system called "Bourbon Restoration".

Palavras chave/Keywords:

Conflictividad social; Sociedad rural; Huelgas agrarias; Motines; Restauración.

Social disputes; Rural society; Agrarian strikes; Riots; Bourbon Restoration. 
El 29 de diciembre de 1874, el general Martínez Campos protagonizaba un pronunciamiento militar que ponía fin a las iniciativas democráticas que se habían sucedido en España desde la revolución de 1868. De este modo se reinstauraba la monarquía de los Borbones en la persona de Alfonso XII. Este acontecimiento iniciaba el régimen político conocido como la Restauración.

Dicho período estuvo marcado por un sistema político donde los dos partidos adscritos al régimen (los conservadores de Antonio Cánovas y los liberales de Mateo Sagasta) se alternaban en el poder mediante un sistema electoral caciquil donde las redes clientelares garantizaban la victoria de unos u otros, lo que se ha conocido como el sistema de turno de partidos ${ }^{1}$. El nuevo sistema se basaba en una política de notables o de salón y, por ello mismo, en la despolitización y la desmovilización de las clases populares². El sistema funcionó sin apenas fisuras durante todo el último cuarto del siglo XIX. Ni siquiera la aprobación de la Ley de Asociaciones de 1887 -que permitió la organización asociativa de los movimientos sociales obreros y/o católicos $^{3}$ - o la Ley Electoral de 1890 que sancionaba el sufragio universal masculino ${ }^{4}$, consiguieron modificar en exceso los resultados electorales.

Sin embargo todo cambió en 1898. Ese año, la marina estadounidense derrotó a la española en las costas de Cuba, y España perdió la soberanía sobre Cuba, Puerto Rico y las islas Filipinas, o lo que es lo mismo, se puso fin a un imperio centenario que hundía sus raíces en los mismos orígenes de la

1 VARELA ORTEGA, José - Los amigos politicos. Partidos, elecciones y caciquismo en la Restauración, 1875-1900. Madrid: Alianza, 1977; ÍD. (dir.) - El poder de la influencia. Geografia del caciquismo en España (1875-1923). Madrid: Marcial Pons, 2000.

2 ÁLVAREZ JUNCO, José - Estado y sociedad en España durante la década de 1890 in FUSI, Juan P. y NIÑO, A. (dirs.) - Visperas del 98. Orígenes y antecedentes de la crisis del 98. Madrid: Editorial Biblioteca Nueva, 2000, p. 47-64.

3 MAZAZORRILLA, Elena - Nuevas formas y espacios de sociabilidad al filo del siglo XX in GÓMEZ-FERRER MORANT, Guadalupe y SÁNCHEZ, Raquel (eds.) - Modernizar España. Proyectos de reforma y apertura internacional (1898-1914). Madrid: Ediciones Biblioteca Nueva, 2007, p. 119-142. Tal es el caso de las Sociedades de Socorros Mutuos. MAZA ZORRILLA, Elena - La horizontalidad de las solidaridades. El mutualismo en la España contemporánea. Ayer, 25 (1997) 73-102.

4 En regiones agrarias como Aragón o Castilla y León, la ley de 1890 supuso que más del $70 \%$ de la población masculina tuviera derecho a voto. FRÍAS CORREDOR, Carmen y GARCÍA ENCABO, Carmelo - Sufragio universal masculino y politización campesina en la España de la Restauración (1875-1923). Historia Agraria, 38 (2006) 27-46. 
unidad del reino de España, allá por inicios del siglo XVI. Esta derrota abrió una profunda crisis de identidad nacional agitada desde la opinión pública, la cual supuso un violento terremoto político que sacudió furiosamente el edificio de la Restauración, sufriendo éste serios daños estructurales ${ }^{5}$. La mayor manifestación de esta crisis fue la corriente literaria de los regeneracionistas, un grupo de intelectuales que cuestionaron duramente la legitimidad del sistema político y plantearon profundas reformas ${ }^{6}$.

Pero no sólo mostraron su indignación con el sistema político los intelectuales. Como señaló S. Tarrow, los más intensos ciclos de protesta popular se originan cuando las muestras de debilidad de los regímenes políticos crean nuevas «oportunidades políticas» ${ }^{7}$. La España de 1898 siguió este patrón, y a la crisis de identidad nacional se unió una incipiente e inusitada movilización política de las clases populares. Este fenómeno llevó a uno de aquellos escritores regeneracionistas, Joaquín Costa, a preguntarse si no había llegado la hora «de que llegue su turno al pueblo», en clara alusión al sistema de turno de partidos. Esta expresión fue asumida y reutilizada por C. Serrano en una obra donde analizaba la evolución de la movilización popular durante los años del cambio de siglo ${ }^{8}$.

La movilización popular iniciada en 1898 culminará en 1923 cuando el sistema político de la Restauración se derrumbe definitivamente tras un nuevo desastre militar -en Annual (Marruecos) en 1921- y una nueva oleada de conflictos sociales -iniciada con la huelga general de ferrocarriles en agosto de $1917-9$.

5 TUÑÓN DE LARA, Manuel - España: la quiebra de 1898. Madrid: Sarpe, 1986; BALFOUR, Sebastián - El fin del imperio español (1898-1923). Barcelona: Crítica, 1997; PAN-MONTOJO, Juan (coord.) - Más se perdió en Cuba. España 1898 y la crisis de fin de siglo. Madrid: Alianza, 1998; FUSI, Juan P. y NIÑO, Antonio (dirs.) - Visperas del 98..., cit.

6 ARÓSTEGUI, Julio - Los regeneracionistas y el 98 in GIRÓN GARROTE, José Un cambio de siglo, 1898. España, Cuba, Puerto Rico, Filipinas y Estados Unidos. Oviedo: Universidad de Oviedo, 2008, p. 115-120

7 TARROW, Sidney - Power in Movement. Collective Action, Social Movements and Politics. New York: Cambridge University Press, 1994.

8 SERRANO, Carlos - El turno del pueblo. Crisis nacional, movimientos populares y populismo en España (1890-1910). Barcelona: Península, 2000 (1 ${ }^{\text {a }}$ edición escrita en francés en 1987).

9 GARCÍA DELGADO, José L. (coord.) - La crisis de la Restauración. España entre la Primera Guerra Mundial y la Segunda República. Madrid: Siglo XXI, 1986; BARRIO 
En este contexto, ¿qué papel tuvieron los campesinos? Durante largo tiempo, en la historiografía española ha dominado la idea de que esta movilización popular se restringió a los obreros industriales en donde cuajaron los idearios socialistas y anarquistas. Los campesinos, por su parte, fueron apartados del discurso histórico basándose en la visión regeneracionista de un campesinado «persuadido de que nadie remediará sus infortunios y de que sus únicos derechos son obedecer, pagar, sufrir y callar» ${ }^{10}$. Y todo ello a pesar de que el campesinado español fue uno de los sectores sociales más desfavorecidos a finales del siglo XIX, debido a la conocida como crisis finisecular $^{11}$. La principal consecuencia de esta situación fue la apertura de un proceso de proletarización de los pequeños propietarios y arrendatarios ${ }^{12} ; \mathrm{y}$, a la sazón, el desarrollo de una importante ola migratoria desde las zonas rurales españolas hacia las grandes ciudades o al extranjero ${ }^{13}$.

Afortunadamente, desde hace dos décadas un variado grupo de investigadores ha sacado a la luz esa rebeldía campesina hasta ahora soterrada, logrando introducir en el debate historiográfico español el turno de los campesinos. En este sentido, este artículo propone analizar, por un lado, la evolución de los estudios historiográficos de la protesta social campesina en España; y, por otro, mostrar la conflictividad social protagonizada por el campesinado español a través de los tres grandes ciclos de conflictividad social que tuvieron lugar durante a la crisis de la Restauración, es decir, los años 1898, 1903-05 y 1918-20.

ALONSO, Ángeles (coord.) - La crisis del régimen liberal en España (1917-1923). Ayer. 63 (2006).

${ }^{10}$ SENADOR GÓMEZ, Julio - Castilla en escombros: las leyes, las tierras, el trigo y el hambre. Valladolid: Ámbito, 1993 (1ª ed. 1915).

${ }^{11}$ GARRABOU, Ramón (ed.) - La crisis agraria de finales del siglo XIX. Barcelona, Crítica, 1988.

${ }^{12}$ GARRIDO GONZÁLEZ, Luis - La configuración de una clase obrera agrícola en la Andalucía contemporánea: los jornaleros. Historia Social. 28 (1997), 41-67.

${ }^{13}$ SÁNCHEZ ALONSO, Blanca - Las causas de la emigración española (1880-1930). Madrid: Crítica, 1995. 


\section{La historiografía española sobre la protesta social campesina de la Restauración}

Los estudios sobre protesta popular se iniciaron en la década de los sesenta del siglo pasado al amparo de la historiografía marxista clásica, vinculándose a la historia del movimiento obrero. Desde este punto de vista se consideraba el conflicto como una lucha exclusiva entre la burguesía y el proletariado (lucha de clases). La principal causa de esta visión fue que los historiadores marxistas ortodoxos, y no tan ortodoxos, marginaron a los campesinos del discurso historiográfico, una marginación que también se fomentó desde las teorías de la historiografía liberal. De este modo, se puede decir que «tanto para los marxistas como para los liberales, el campesino era, por su propia naturaleza social, incapaz de incorporarse a la modernidad», creándose una «visión aún predominante [que] niega protagonismo alguno al mundo rural y al campesinado en el proceso de democratización o en la construcción nacional o en la modernización socioeconómica de nuestro país» ${ }^{14}$. En el caso español, los historiadores comenzaron a publicar investigaciones en los años setenta poniendo su foco de atención las grandes ciudades y las regiones industriales periféricas peninsulares. En este contexto, hubo una excepción que atendió al mundo rural, los estudios en torno a la clase jornalera de la Andalucía latifundista relacionados con la reforma agraria y la influencia que tuvo el anarquismo en la región ${ }^{15}$.

${ }^{14}$ GONZÁLEZ DE MOLINA, Manuel - Algunas reflexiones sobre el mundo rural y los movimientos campesinos en la Historia contemporánea española in RIVERA, Antonio; ORTIZ DE ORRUÑO, José M.; y UGARTE, Javier (eds.) - Movimientos sociales en la España Contemporánea. Madrid: Abada Editores, 2008, p. 97-126.

${ }^{15}$ MALEFAKIS, Edward - Reforma agraria y revolución campesina en la España del siglo XX. Barcelona: Ariel, 1971; BERNAL, Antonio M. - La propiedad de la tierra y las luchas agrarias campesinas. Barcelona: Ariel, 1974; CALERO AMOR, Antonio M. - Movimientos sociales en Andalucía (1820-1936). Madrid: Siglo XXI, 1976; KAPAN, Temma - Los orígenes sociales del anarquismo en Andalucía. Capitalismo agrario y lucha de clases en la provincia de Cádiz, 1868-1903. Barcelona: Crítica, 1977; TUÑÓN DE LARA, Manuel - Luchas obreras y campesinas en la Andalucía del siglo XX. Jaén (1917-1920). Sevilla (1930-1932). Madrid: Siglo XXI, 1978; SEVILLA GUZMÁN, Eduardo y HEISEL, Karl (eds.) - Anarquismo y movimiento jornalero en Andalucía. Córdoba: Ayuntamiento de Córdoba, 1988; MAURICE, Jacques - El anarquismo andaluz. Campesinos y sindicalistas, 1868-1936. Barcelona: Crítica, 1989. Al amparo de estos estudios surgieron aisladas investigaciones sobre otras regiones españolas, por ejemplo: ARÓSTEGUI, Julio - Miseria 
Los trabajos dedicados al movimiento obrero tenían como objeto analizar todas aquellas manifestaciones de protesta popular «modernas» vinculadas a partidos y sindicatos de ideología obrera, dejando en la sombra a las «primitivas» formas de protesta popular - motines, revueltas, disturbios o alborotos- que eran consideradas, si no explícitamente, sí implícitamente, como residuos irracionales del Antiguo Régimen.

Fue durante los mismos años sesenta, al socaire de los procesos de descolonización, las revueltas campesinas del Tercer Mundo y el nacimiento de los Nuevos Movimientos Sociales, cuando dentro de la escuela marxista británica se comenzó a cuestionar el paradigma explicativo de la historia del movimiento obrero. E. J. Hobsbawm, E. P. Thompson y G. Rudé rehabilitaron historiográficamente a las «primitivas» formas populares de protesta, señalando cómo éstas no eran ni tan primitivas, ni tan extrañas, ni mucho menos tan irracionales ${ }^{16}$. Estos trabajos historiográficos se vieron completados por la labor de sociólogos como E. R. Wolf y T. Shanin ${ }^{17}$; y también de aquéllos que se dedicaron al estudio de las formas de protesta colectiva, entre los que destacó C. Tilly ${ }^{18}$. El primer reflejo que tuvo esta nueva concepción de la protesta popular en la historiografía española vino de la mano de J. Torras ${ }^{19}$.

Sin embargo, no fue hasta los primeros años ochenta, cuando J. Álvarez Junco y M. Pérez Ledesma advirtieron la ausencia de interés entre los historiadores españoles por los nuevos enfoques teóricos y metodológicos en el estudio de la protesta social, proponiendo, a su vez, ampliar el tradicional

y conciencia del campesinado castellano. ("Memoria acerca de la información agraria en ambas Castillas»). Madrid: Narcea, 1977.

${ }^{16}$ Las obras más influyentes de estos autores son: HOBSBAWM, Eric J. - Primitive Rebels. Studies in Archaic Forms of Social Movement in the 19th and 20th Centuries. Manchester: Manchester University Press, 1959; THOMPSON, Edward P., The Making of the English Working Class. London: Victor Gollancz Ltd, 1963; RUDÉ, George - The Crowd in History. A Study of Popular Disturbances in France and England, 1730-1848. New York, Wiley, 1964.

${ }^{17}$ WOLF, Eric R., Peasants. New Jersey: Prentice Hall, 1966; SHANIN, Teodor (ed.) - Peasans and Peasant Societies. Baltimore: Penguin Books, 1971.

18 TILLY, Charles; TILLY, Louise A. y TILLY, Richard - The Rebellious Century. 1830-1930. Cambridge: Harvard University Press, 1975; y TILLY, Charles - From Mobilization to Revolution. New York: Random House, 1978.

19 TORRAS, Jaime - Liberalismo y rebeldia campesina, 1820-1823. Barcelona: Ariel, 1976. 
concepto de «historia del movimiento obrero» hacia el de «historia de los movimientos sociales», en donde cabían todas las manifestaciones populares de protesta y resistencia ${ }^{20}$. A partir de este momento surgieron multitud de estudios que analizaban genéricamente las formas de protesta colectiva ajenas al movimiento obrero ${ }^{21}$; así como tipos y ciclos concretos de protesta tradicional como eran los motines de subsistencias ${ }^{22} \mathrm{o}$ las protestas antifiscales ${ }^{23}$.

Pero, a pesar de todo, en 1995, C. Gil Andrés hacía balance de la producción historiográfica española desde la propuesta rupturista de J. Álvarez Junco y M. Pérez Ledesma, señalando que:

${ }^{20}$ ÁlVAREZ JUNCO, José y PÉREZ LEDESMA, Manuel - Historia del movimiento obrero: ¿Una segunda ruptura? Revista de Occidente. 12 (1982) 19-41.

${ }^{21}$ GIL NOVALES, Alberto - La conflictividad social bajo la Restauración (18751917). Trienio. 7 (1986) 73-217; SÁNCHEZ JIMÉNEZ, José - Conflictividad y dinámica social agraria: la inserción del campesinado en el movimiento obrero. Anales de Historia Contemporánea. 5 (1986) 77-92; CASTRO ALFÍN, Demetrio - Agitación y orden en la Restauración ¿Fin de ciclo revolucionario? Historia Social. 5 (1989) 37-49; PÉREZ LEDESMA, Manuel - Estabilidad y conflicto social. España, de los íberos al 14-D. Madrid: Nerea. 1990, p. 165-202; PÉREZ GARZÓN, Juan S. y DEL REY SEGUILLO, Fernando - Conflictos y protestas. De la ciudad liberal a la ciudad democrática, 1808-1978 in BONAMUSA, Francisco y SERRALLONGA, Joan (eds.) - La sociedad urbana en la España contemporánea. Actas del II Congreso de la AHC. Barcelona: Asociación de Historia Contemporánea, 1994, p. 273-305; CRUZ MARTÍNEZ, Rafael - El mitin y el motín. La acción colectiva y los movimientos sociales en la España del siglo XX. Historia Social. 31 (1998) 137-152.

${ }^{22}$ SERRANO, Carlos - Guerra y crisis social: los motines de mayo del 98 in CASTILLO, Santiago; FORCADELL, Carlos; GARCÍA-NIETO, María C. y PÉREZ GARZÓN, Juan S. (coords.) - Estudios sobre Historia de España. Homenaje a Tuñón de Lara, I. Madrid: Universidad Internacional Menéndez Pelayo, 1981, p. 439-449 y El turno del pueblo. Crisis nacional, movimientos populares y populismo en España (1890-1910). Barcelona: Península, 2000, p. 49-62; ELORZA, Antonio - Socialismo y agitación popular en Madrid (1908-1920). Estudios de Historia Social. 18-19 (1981) 229-261; ARRIERO, María L. - Los motines de subsistencias en España, 1895-1905. Estudios de Historia Social. 30 (1984) 193-250; SERRALLONGA I URQUIDI, Joan - Motines y revolución. España, 1917. Ayer. 4 (1991). 169-192; BALFOUR, Sebastián - El fin del imperio español... cit., p. 101-140.

${ }^{23}$ VALLEJO POUSADA, Rafael - Pervivencia de las formas tradicionales de protesta: los motines de 1892. Historia Social. 8 (1990) 3-27 y El impuesto de Consumos y la resistencia antifiscal en la España de la segunda mitad del siglo XIX: un impuesto no exclusivamente urbano. Revista de Historia Económica. Año XIV. 2 (1996) 339-370; CASTRO ALFÍN, Demetrio - Protesta popular y orden público: los motines de consumos in GARCÍA DELGADO, José L. (ed.) - España entre dos siglos (1875-1931). Continuidad y cambio. Madrid: Siglo XXI, 1991, p. 109-123. 
«... los vientos renovadores pierden fuerza y sentido si vamos más allá de la superficie y de los títulos y las primeras páginas de numerosos trabajos. En efecto, como una especie de fórmula de compromiso para ganar franquía, en muchas introducciones abundan los apuntes teóricos y metodológicos, y se repiten declaraciones de intenciones y buenos propósitos que no vemos después madurar en los textos. Desde luego, los frutos de la ruptura no parecen haber alcanzado la altura de las expectativas $\rangle^{24}$

Efectivamente, los estudios aludidos resultaban excesivamente generalistas, comúnmente no combinan diversos tipos de fuentes, carecían de interdisciplinariedad o pasaban por alto aspectos tan importantes en la comprensión de los movimientos de protesta como las mentalidades y culturas populares.

En el caso concreto del estudio de la conflictividad propia del campesinado los resultados eran todavía más precarios, de modo que en el año 2000 S. Cruz Artacho calificó el estudio de la conflictividad social campesina como "el «hermano pobre» de la historia social española"25.

Otra de las grandes lagunas de que pecaban los trabajos publicados hasta ese momento, salvo raras excepciones, era la ausencia de referencias a las «formas cotidianas de resistencia campesina» de J. C. Scott ${ }^{26}$, es decir a:

${ }^{24}$ GIL ANDRÉS, Carlos - Protesta popular y movimientos sociales en la Restauración: los frutos de la ruptura. Historia Social. 23 (1995) 121-135. La cita es de las p. 121-122.

${ }^{25}$ CRUZ ARTACHO, Salvador - El «hermano pobre» de la historia social española. Algunas consideraciones sobre el conflicto campesino en la Historia Contemporánea in CASTILLO, Santiago y FERNÁNDEZ, Roberto (coords.) - Historia social y ciencias sociales. Actas del IV Congreso de Historia Social de España. Lérida: Milenio Actas, 2001, p. 245-289.

${ }^{26}$ SCOTT, James C. - Weapons of the Weak. Everyday Forms of Peasant Resistance. New Haven: Yale University Press, 1985. Las excepciones de que habla C. Gil Andrés son los casos de COBO ROMERO, Francisco; CRUZ ARTACHO, Salvador; y GONZÁLEZ DE MOLINA, Manuel - Privatización del monte y protesta campesina en Andalucía oriental (1836-1920). Agricultura y Sociedad. 65 (1992) 253-302; y los trabajos de SÁNCHEZ MARROYO, Fernando - La delincuencia «sociopolítica» en Cáceres durante la Segunda República. Norba. 10 (1989-1990) 233-264; Delincuencia y derecho de propiedad. Una nueva perspectiva del problema social durante la Segunda República. Historia Social. 14 (1992) 25-46; y Movimientos populares y reforma agraria. Tensiones sociales en el campo extremeño durante el Sexenio Democrático (1868-1873). Badajoz: Diputación Provincial de Badajoz, 1992. 
«... cualquier acto(s) [realizado] por miembro(s) de esta clase [campesina] cuya intención sea mitigar o negarse a peticiones (ej. rentas, impuestos, deferencia) impuestas por clases superiores (ej. terratenientes, el estado, propietarios de la maquinaria, prestamistas) o avanzar en sus propias peticiones (ej. trabajo, tierras, caridad, respeto) frente a estas clases superiores ${ }^{27}$

Como solución a todas estas faltas C. Gil Andrés propuso realizar:

«... estudios de ámbitos más reducidos, investigaciones de carácter local que permitan profundizar en la estructura interna de los grupos y las comunidades y descubrir la continuidad de estas acciones tenaces y arraigadas, como el impago de impuestos y contribuciones, la evasión del servicio militar, el furtivismo, las prácticas delictivas relacionadas con el uso del monte, los incendios, sabotajes y otros atentados contra la propiedad que nos muestran que el conflicto es un elemento central de la vida cotidiana de la población [...] volver con luz nueva sobre los documentos de los archivos y las investigaciones concretas $\rangle^{28}$

Al socaire de estas propuestas, desde la segunda mitad de los años noventa del pasado siglo hasta el presente, se han sucedido numerosos trabajos de investigación centrados en marcos geográficos regionales que han profundizado de manera notable en la comprensión de los fenómenos de protesta popular. Además muchos de éstos han atendido de forma especial a regiones rurales del interior peninsular, las cuales $-\mathrm{y}$ salvo la Andalucía latifundista-, eran consideradas lagunas de paz social.

El primer paso en este sentido lo dio S. Cruz Artacho, quien combinó el estudio del poder político local y el desarrollo de la economía agraria con la conflictividad social del campesino granadino. Otros autores han seguido haciendo camino con sus investigaciones ${ }^{29}$. La diversificación de fuentes que

${ }^{27}$ SCOTT, James C. - Formas cotidianas de rebelión campesina. Historia Social. 28 (1997) p. 31. Sobre el estudio de las resistencias individuales del campesinado en la historiografía española véase CASANOVA, Julián - Resistencias individuales, acciones colectivas: nuevas miradas a la protesta social agraria en la historia contemporánea de España in GONZÁLEZ DE MOLINA, Manuel (ed.) - La historia de Andalucía a debate. I. Campesinos y jornaleros. Barcelona: Anthropos; Diputación Provincial de Granada, 2000, p. 289-301.

${ }^{28}$ GIL ANDRÉS, Carlos, Protesta popular... cit., p. 128 y 131.

${ }^{29}$ CRUZ ARTACHO, Salvador - Caciques y campesinos. Poder político, modernización agraria y conflictividad rural en Granada, 1890-1923. Madrid: Ediciones Libertarias; 
han utilizado estos investigadores ha permitido dar un nuevo significado y una nueva dimensión a la protesta popular del campesinado español.

Por otro lado, asimismo el «efecto Scott» ha tenido un notable éxito en la historiografía española vinculándose a la historia ecológica y a la «delincuencia forestal». Es decir, todo ese repertorio de prácticas ilegales (caza furtiva, pastoreo abusivo, roturaciones ilegales, etc.) a través de las cuales los campesinos se resistían a la pérdida de los comunales $^{30}$ derivada de las reformas liberales, un proceso que amenazaba directamente los tradicionales sistemas de reproducción social de las comunidades rurales ${ }^{31}$.

Ayuntamiento de Córdoba, 1994, p. 465-574; GIL ANDRÉS, Carlos - Protesta popular y orden social en La Rioja de fin de siglo, 1890-1905. Logroño: Instituto de Estudios Riojanos, 1995, y Echarse a la calle. Amotinados, huelguistas y revolucionarios (La Rioja, 1890-1936). Zaragoza: Prensas Universitarias de Zaragoza, 2000; BAUMEISTER, Martin - Campesinos sin tierra. Supervivencia y resistencia en Extremadura, 1880-1923. Badajoz: Diputación Provincial de Badajoz, 1996; CABO VILLAVERDE, Miguel - O Agrarismo. Vigo: Edicions a Nosa Terra, 1998; GASTÓN AGUAS, José M. - ;Arriba jornaleros! Los campesinos navarros ante la revolución burguesa (1841-1868). Tafalla (Navarra): Txalaparta, 2003 y Los campesinos navarros ante la revolución burguesa, 1841-1868. Historia Social. 46 (2003) p. 25-48; LUCEA AYALA, Víctor - Rebeldes y amotinados. Protesta popular y resistencia campesina en Zaragoza (1890-1905). Zaragoza: Institución «Fernando el Católico», 2005 y El pueblo en movimiento. La protesta social en Aragón (1885-1917). Zaragoza: Prensas Universitarias de Zaragoza, 2009; BASCUÑÁN AÑOVER, Óscar-Protesta y supervivencia. Movilización y desorden en una sociedad rural: Castilla-La Mancha. Alzira (Valencia): Fundación Instituto de Historia Social, 2008; REDONDO CARDEÑOSO, Jesús-Ángel - Protesta y violencia de los campesinos castellano-leoneses: la Tierra de Campos (1900-1923), Palencia, Diputación de Palencia/Diputación de Valladolid, 2011, p. 35-210.

${ }^{30}$ Según el Diccionario de la Real Academia Española (DRAE), los bienes comunales son aquellos que «pertenecen a un municipio u otra entidad local y están destinados al aprovechamiento de sus vecinos».

${ }^{31}$ HERVÉS SAYAR, Henrique et alii - Resistencia y organización. La conflictividad rural en Galicia desde la crisis del Antiguo Régimen al franquismo. Noticiario de Historia Agraria. 13 (1997) 165-191; SALA LÓPEZ, Pere-Conflictividad rural en el monte comunal gerundense: pueblos y mansos ante el Estado interventor en la segunda mitad del siglo XIX. Noticiario de Historia Agraria. 13 (1997) 105-124; SABIO ALCUTÉN, Alberto - Los montes públicos en Huesca (1859-1930). El bosque no se improvisa. Huesca: Instituto de Estudios Altoaragoneses, 1997, p. 191-223, e Imágenes del monte público, «patriotismo forestal español» y resistencias campesinas, 1855-1930. Ayer. 46 (2002) 123-153; DE LA TORRE, Joseba y LANA BERASAIN, José M. - El asalto a los bienes comunales. Cambio económico y conflictos sociales en Navarra, 1808-1936. Historia Social. 37 (2000) 75-95; CRUZ ARTACHO, Salvador - De campesino a ladrón y delincuente en Andalucía (XIX-XX) in GONZÁLEZ DE MOLINA, Manuel (ed.) - La historia de Andalucía a debate. I... cit., p. 159-178; FRÍAS CORREDOR, Carmen - Conflictividad, protesta y formas de resistencia en el mundo rural. Huesca, 1880-1914. Historia Social. 37 (2000) 97-118; GONZÁLEZ DE MOLINA, Manuel y ORTEGA SANTOS, Antonio - Bienes comunales y conflictos por 
En definitiva, a pesar del abandono que los historiadores durante mucho tiempo habían legado al campesinado español, desde los últimos quince años hasta hoy, paso a paso, y con la aportación de numerosos investigadores procedentes de muy diversas regiones españolas, se está haciendo posible que el campesinado sea un actor visible dentro del discurso histórico nacional, lo cual esperamos y deseamos que siga sucediendo con las aportaciones de futuras nuevas generaciones de historiadores.

\section{Los ciclos de conflictividad social campesina entre 1898 y 1923}

\section{1) 1898: la última crisis de subsistencias del siglo XIX}

El 1 de mayo de 1898, en Cavite (Filipinas), la flota española fue derrotada por buques estadounidenses poniendo práctico fin a la soberanía española sobre las islas. Al día siguiente, llegaron a España las noticias de la derrota. A primera hora de la mañana de ese mismo día, un grupo de mujeres iniciaban un motín en el puerto de Gijón que derivó en graves disturbios populares, asaltos a almacenes de grandes comerciantes y barricadas callejeras. Casi al mismo tiempo, en Talavera de la Reina, cabeza de comarca agrícola del interior peninsular, la multitud también se echó a la calle, terminando por asaltar e incendiar varios establecimientos comerciales, la estación de ferrocarril y el convento de los Jesuitas. Según los datos de C. Serrano, durante las dos siguientes semanas, se sucedieron motines, disturbios y alborotos por más de sesenta localidades españolas ${ }^{32}$. ¿Qué llevó a estas masas populares a echarse a la calle tumultuariamente? Estas manifestaciones de protesta poco

los recursos en las sociedades rurales, siglos XIX y XX. Historia Social. 38 (2000) 95-116; ORTEGA SANTOS, Antonio - La desarticulación de la propiedad comunal en España, siglos XVIII-XX: una aproximación multicausal y socioambiental a la historia de los montes públicos. Ayer. 42 (2001) 191-211, y La tragedia de los cerramientos. Desarticulación de la comunalidad en la provincia de Granada. Alzira (Valencia): Fundación Instituto de Historia Social, 2002, p. 247-311; GASTÓN AGUAS, José M. - La protesta por el comunal en la zona media de Navarra, 1841-1923. Historia Contemporánea. 26 (2003) 291-327; BASCUÑÁN AÑOVER, Óscar - Delincuencia y desorden social en la España agraria. La Mancha, 1900-1936. Historia Social. 51 (2005) 111-138.

32 SERRANO, Carlos - El turno del pueblo... cit., p. 52. 
tuvieron que ver con la derrota española en Filipinas ni con la crisis de la identidad nacional que comenzará a engendrarse desde ese momento entre los regeneracionistas. Muy al contrario, la guerra nunca fue bien acogida entre las clases populares, como muy bien refleja Miguel de Unamuno, esta vez ante la derrota naval española en Santiago de Cuba:

«El día mismo del desastre de la escuadra de Cervera, hallábame yo acordonado desde hacía días [...] en una dehesa en cuyas eras trillaban en paz su centeno los labriegos, ignorantes de cuanto a la guerra se refiere, y estoy seguro de que eran en toda España muchísimos más los que trabajaban en silencio, preocupados tan sólo por el pan de cada día, que los inquietos por los públicos sucesos $»^{33}$

El escritor bilbaíno no podía tener más razón. Por encima de lo que sucedía a más de 7.000 kilómetros de distancia, lo que realmente importaba a las clases populares españolas era «el pan de cada día». Las mujeres que iniciaron los disturbios en Gijón protestaban por los altos precios del pescado; y la multitud de Talavera de la Reina reclamaba pan barato y trabajo ${ }^{34}$.

Y es que España vivía en esos años bajo una profunda crisis de subsistencias. En 1898 se produjo un notable aumento del precio del trigo principalmente causado por el hundimiento de la peseta, el cual se acentuó con el conflicto militar ${ }^{35}$. La consecuencia inmediata fue la subida de los precios de los alimentos de primera necesidad que tenía más incidencia sobre las economías familiares de las clases populares.

El descontento de las clases populares por estas subidas no tardó en manifestarse. Ya desde febrero de 1898 se produjeron alteraciones del orden público bajo los gritos de «¡Pan y trabajo!» en capitales de provincia castellanas como Salamanca o Palencia ${ }^{36}$. Si bien no será hasta las dos

${ }^{33}$ Citado en FERNÁNDEZ ALMAGRO, Melchor - Historia politica de la España Contemporánea. Vol. 2. Madrid: Pegaso, 1959, p. 621.

${ }^{34}$ Sobre el motín de Gijón véase RADCLIFF, Pamela B. - De la movilización a la Guerra Civil. Historia política y social en Gijón (1900-1937). Barcelona: Debate, 2004, p. 70-72; sobre el de Talavera de la Reina véase DÍAZ DÍAZ, Benito - La protesta popular en Talavera: el motín del pan de 1898. Cuaderna. 1 (1994) 76-90.

${ }^{35}$ SERRANO, Carlos - El turno del pueblo... cit. p. 50-51; BALFOUR, Sebastián El fin del imperio español... cit., p. 114.

${ }^{36}$ RABATÉ, Jean-Claude - 1900 en Salamanca. Guerra y paz en la Salamanca del joven Unamuno. Salamanca: Universidad de Salamanca, 1997, p. 90-98; PELAZ LÓPEZ, 
primeras semanas de mayo cuando los motines y disturbios en protesta por los altos precios de los comestibles se extiendan por todo el país.

Gráfico 1 - Precio del trigo en España, 1894-1906

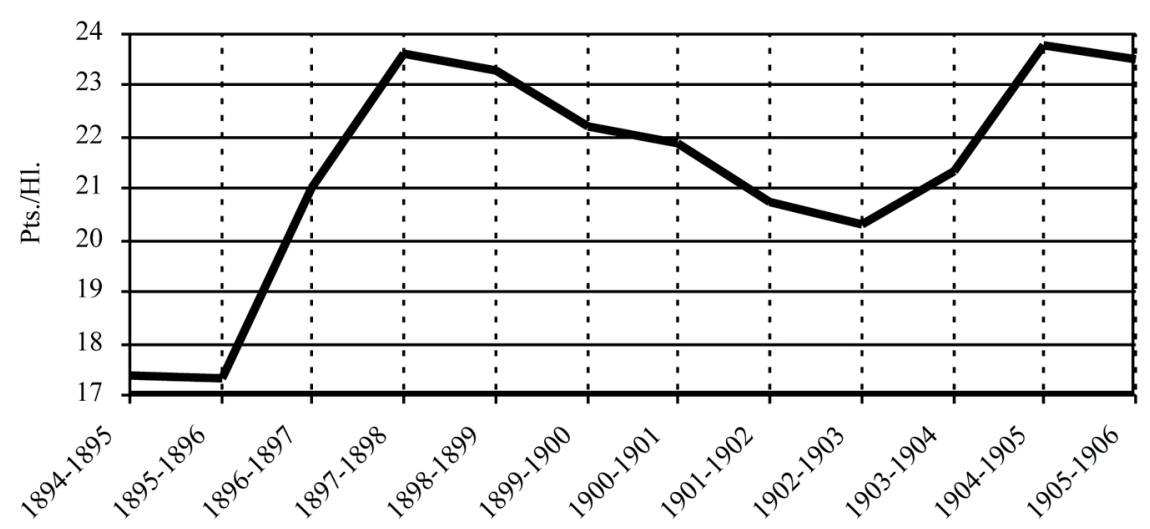

Fuente: GRUPO DE ESTUDIOS DE HISTORIA RURAL - Los precios del trigo y la cebada en España, 1891-1907. Madrid: Banco de España, 1980, p. 170. Elaboración propia.

Estos conflictos se concentraron en ciudades de segundo orden como capitales de provincia y/o cabeceras de comarcas agrícolas, quedando al margen las grandes ciudades (Madrid, Barcelona, Valencia). Es decir, las zonas más afectadas fueron las que más sufrieron la crisis finisecular. Al mismo tiempo destacaron las protestas en los centros mineros (Bilbao; Langreo y Mieres en Asturias; Belmez y Linares en Andalucía; La Unión en Murcia, etc.).

¿Qué papel tuvieron los campesinos en estos sucesos? En un principio podría parecer que la agitación no tuvo incidencia en los pequeños núcleos rurales españoles, a pesar de que dichos conflictos estuvieran íntimamente ligados a la crisis finisecular y al ascenso del precio del trigo. Nada más lejos de la realidad. Como el propio C. Serrano señala: «en realidad la agitación fue ciertamente más amplia aún, dado que la prensa informa muchas veces de revueltas en algunos pueblos que no menciona» ${ }^{37}$.

José V. - Prensa, poder y sociedad en Palencia (1808-1941) (tesis doctoral). Valladolid: Universidad de Valladolid, 1998, p. 272-273.

${ }^{37}$ SERRANO, Carlos - El turno del pueblo ... cit. p. 52-54. 
En efecto, si superamos los estudios de C. Serrano, basados en informaciones de diarios nacionales (La Correspondencia de España y Diario de Barcelona) o en la documentación del Ministerio de Asuntos Exteriores, y nos acercamos a investigaciones que han utilizado prensa y documentación de ámbito local, provincial y/o regional, podemos ver el verdadero alcance que tuvieron las protestas de 1898.

Por ejemplo, en el caso de la provincia de Badajoz, mientras C. Serrano contabilizó cuatro motines, M. Baumeister elevó el número a catorce, todos ellos ocurridos entre el 5 y el 9 de mayo bajo la petición común de que se bajara del precio del pan y se prohibiera las exportaciones de $\operatorname{granos}^{38}$. Un caso similar encontramos en la provincia de Logroño donde mientras el primer autor localizó un único motín en la capital provincial, C. Gil Andrés señala una revuelta ya en 1897 , cinco más antes de que llegara mayo de 1898, y otras cinco alteraciones del orden público en los primeros días de este mes $^{39}$. En el caso de las cinco provincias que conforman la actual región de Castilla-La Mancha, frente a los ocho motines que registró C. Serrano, O. Bascuñán Añover elevó dicha cifra a cincuenta y tres acciones populares de diversa consideración, de las cuales veinticuatro correspondieron a la provincia de Toledo, diecinueve a la de Ciudad Real, cinco a Albacete, tres a Cuenca y una a Guadalajara -si bien en esta última, el mismo autor localizó seis motines a lo largo de 1897, uno de ellos en la propia capital-40.

La mayoría de todos estos nuevos conflictos se localizaron en pequeñas localidades rurales, y sus protagonistas, por tanto, fueron campesinos. Es decir, a tenor de los ejemplos expuestos, consideramos que no nos alejamos mucho de la realidad si afirmamos que, durante mayo de 1898, una buena parte del campesinado español salió a la calle espoleado por la crisis del país, exigiendo a las autoridades locales y provinciales que controlasen los precios de los productos básicos, tomasen medidas para evitar el desabastecimiento de las localidades y/o ofrecieran trabajo a las clases más desfavorecidas.

\footnotetext{
${ }^{38}$ BAUMEISTER, Martin - Campesinos sin tierra ... cit., p. 280-283.

${ }^{39}$ GIL ANDRÉS, Carlos - Echarse a la calle ... cit., p. 39-44.

${ }^{40}$ BASCUÑÁN AÑOVER, Óscar - Protesta y supervivencia ... cit., p. 74-88.
} 


\section{2) 1903-1905: entre los motines decimonónicos y la organización campesina}

Si volvemos a echar un vistazo al gráfico 1 podremos ver que tras 1898 , se produjo una nueva subida del precio del trigo a partir de 1903, la cual culminaría en 1905, produciéndose una nueva crisis de subsistencias. Una muestra de esta coyuntura fueron nuevamente el desarrollo de motines, como los ocurridos los primeros meses de 1904 en Valencia y Tarragona, contra los consumos, o en Valladolid en petición de pan y trabajo ${ }^{41}$.

La nueva crisis también tuvo influencia en los ámbitos rurales españoles, sin embargo, en los primeros años del siglo XX aparecieron unos nuevos actores políticos. Nos referimos a ideologías de clase como el anarquismo y el socialismo, las cuales calaron en determinadas regiones de España como Andalucía y Castilla, por donde extendieron un nuevo instrumento de protesta colectiva: la huelga.

En el caso del campo de andaluz, la influencia del asociacionismo obrero se dejó sentir desde las últimas décadas del siglo XIX, principalmente en la provincia de Cádiz, de la mano de la Unión de Trabajadores del Campo (UTC), organización campesina de influencia anarquista que pretendía organizar a jornaleros, pequeños propietarios y arrendatarios como medio para mejorar sus condiciones de trabajo. Tras una primera formación en 1872 que fracasó, la UTC resurgió en 1881, extendiendo su influencia por la baja Andalucía. La nueva organización llegó a alcanzar los 20.000 afiliados en septiembre de 1882 y logró plantear una huelga campesina de cara al verano de 1883. El fracaso de ésta derivó en el progresivo debilitamiento de la organización hasta su disolución en 1888. Aún con todo, se siguieron produciendo algunos actos de protesta colectiva, como fue el asalto a la cárcel de Jerez de la Frontera en enero de $1892^{42}$.

${ }^{41}$ A falta de estudios bibliográficos sobre estos sucesos, nos remitimos a prensa escrita contemporánea: El Imparcial, 16-1-1904, 19-1-1904 y 9-3-1904 (consultables en http:// hemerotecadigital.bne.es/cgi-bin/Pandora).

${ }^{42}$ Sobre la UTC véase MAURICE, Jacques - El anarquismo andaluz ... cit., p. 235-257; y para el caso concreto de Jerez de la Frontera y su campiña, MONTAÑÉS, Enrique - Transformación agrícola y conflictividad campesina en Jerez de la Frontera (1880-1923). Cádiz: Universidad de Cádiz; Ayuntamiento de Jerez, 1997, p. 192-208. 
Con la llegada de los primeros años del nuevo siglo se producirá una revitalización del asociacionismo anarquista campesino en Andalucía. El más claro ejemplo de este hecho se produjo en septiembre de 1900, cuando se celebró en la localidad gaditana de Villamartín un congreso de sociedades obreras de las provincias de Cádiz, Sevilla y Málaga, las cuales decían aglutinar a alrededor de veinticuatro mil obreros ${ }^{43}$.

Poco tiempo pasó desde la creación de las sociedades obreras al planteamiento de conflictos laborales. El 27 de diciembre de 1901 se declaró una huelga en El Coronil (Sevilla) que ya en enero de 1902 derivó en una manifestación de mujeres y niños que impedían la entrada en el pueblo de trabajadores forasteros. A lo largo de este mismo último año surgieron nuevos conflictos en Carmona y Morón de la Frontera; y en Jerez, por dos ocasiones. Asimismo se planteó una huelga agrícola en Teba (Málaga), en este caso bajo la influencia de una asociación socialista ${ }^{44}$.

A pesar de todo, no será hasta 1903 cuando las huelgas se generalicen por el valle del Guadalquivir entre los meses de mayo y julio, declarándose un total de trece conflictos laborales campesinos. De éstos, cuatro tuvieron lugar en la provincia de Córdoba, cinco en la de Cádiz, tres en la de Sevilla y una en la de Málaga ${ }^{45}$.

El fin de los conflictos andaluces durante el verano de 1903 tuvo lugar en Alcalá del Valle (Cádiz), cuando el 1 de agosto más de quinientos jornaleros secundaron la huelga general convocada por la Federación Regional Española de Sociedades de Resistencia. Como resultado de la intervención de la Guardia Civil, hubo un enfrentamiento entre guardias y huelguistas, resultando muerto un joven de 15 años. Ante tales hechos, los huelguistas se amotinaron prendiendo fuego al Ayuntamiento y al Juzgado Municipal.

La oleada huelguística andaluza tuvo su eco en otras regiones españolas. Más al norte del país, en La Rioja, en torno a la localidad vinícola de Haro $^{46}$; y en Castilla la Vieja, principalmente en pueblos de las provincias

${ }^{43}$ MONTAÑÉS, Enrique - Transformación agrícola ... cit., p. 210.

${ }^{44}$ La huelga de Teba en BIGLINO, Paloma - El socialismo español y la cuestión agraria, 1890-1936. Madrid: Ministerio de Trabajo, p. 51-55.

${ }^{45}$ MAURICE, Jacques - El anarquismo andaluz ... cit., p. 323-329.

${ }^{46}$ GIL ANDRÉS, Carlos - Echarse a la calle... cit., p. 73-79. 
de Valladolid y Zamora ${ }^{47}$. En estas regiones la dirección de la acción reivindicativa estaba bajo influencia del socialismo, cuyas ideas arribaron la zona a través de los obreros que trabajaban temporalmente en las minas de Vizcaya ${ }^{48}$. Esta influencia se dejó sentir sobre todo en la vasta comarca triguera de Tierra de Campos, que se extiende por las provincias de León, Palencia, Valladolid y Zamora, donde se crearon importante número de sociedades agrícolas en 1903 y 1904, y donde los candidatos asociados obtuvieron significativos triunfos electorales en los comicios municipales del 8 de noviembre de $1903^{49}$.

Sin embargo, a pesar del éxito del socialismo, ante la crisis de subsistencias del invierno de 1903-04 los campesinos castellanos no rechazaron los motines y manifestaciones populares como expresión de protesta colectiva contra el impuesto de Consumos - siete conflictos- o en petición de pan y trabajo -diecisiete conflictos, diez de ellos en pequeños pueblos-. No será hasta febrero de 1904 cuando las sociedades obreras canalicen ese descontento campesino y se extiendan nuevas huelgas agrícolas. Entre febrero y marzo de ese año se declararon conflictos laborales en un total de dieciséis localidades, la mayoría en la mencionada Tierra de Campos. Con la llegada de la primavera, y de cara a las labores estivales de recolección del trigo, los jornaleros castellanos celebraron dos congresos regionales en Villalpando (Zamora) en abril y en Becilla de Valderaduey (Valladolid) en junio, donde se acordaron conjuntamente las reclamaciones de los obreros ante las negociaciones de los jornales veraniegos. Entre junio y julio de 1904 se plantearon huelgas agrícolas en un total de treinta y dos pueblos castellanos, además de varios conflictos de diverso tipo (coacciones, manifestaciones, etc.) en otros trece lugares; la mayoría, de nuevo, en Tierra de Campos $^{50}$. A todas estas contiendas habría que añadir algunas huelgas más ocurridas en la provincia de Toledo ${ }^{51}$.

${ }^{47}$ REDONDO CARDEÑOSO, Jesús-Ángel - 1904. Rebelión en Castilla y León. Valladolid: Universidad de Valladolid, 2013, p. 33-42.

${ }^{48}$ Los cuales a su vez tuvieron una importante participación en la huelga de Vizcaya del otoño de 1903: FUSI, Juan Pablo - Política obrera en el País Vasco, 1880-1923. Madrid: Ed. Turner, 1975, p. 230-242.

${ }^{49}$ BIGLINO, Paloma - El socialismo español... cit., p. 54-57.

${ }^{50}$ REDONDO CARDEÑOSO, Jesús-Ángel - 1904. Rebelión en Castilla y León... cit.

${ }^{51}$ BASCUÑÁN AÑOVER, Óscar - Protesta y supervivencia ... cit., p. 104-108. 
La importancia de esta ola huelguística en Castilla fue tal, que el propio gobierno encargó una investigación al Instituto de Reformas Sociales para determinar las causas de la rebeldía del jornalero castellano. La consecuencia de este estudio es un interesantísimo documento que repasa las condiciones de vida, la evolución del asociacionismo y el alcance de las huelgas de los jornaleros castellanos durante aquel año de $1904^{52}$.

Tanto en Andalucía, como en Castilla, a los correspondientes picos de conflictividad social de los años 1903 y 1904 les sucedieron repentinos ocasos en la protesta campesina y en el asociacionismo sindical agrario en general ${ }^{53}$. Las causas de este fenómeno son variadas, y entre ellas desataca la gran escasez de 1905, que provocó un aumento de la emigración; la reacción de los propietarios agrarios, tanto mediante acciones represivas contra los obreros asociados como mediante la creación de una red de sindicatos católico-agrarios a partir de 1906 como alternativa a los sindicatos de clase ${ }^{54}$; y la poca capacidad de los líderes sindicales nacionales para integrar en su programa a todos los sectores sociales campesinos, principalmente a los pequeños propietarios-arrendatarios, quienes conformaban el sector social más importante de la España rural ${ }^{55}$.

${ }^{52}$ Memoria acerca de la información agraria en ambas Castillas encomendado a este Centro por Real Orden de 25 de Junio de 1904, redactada por Adolfo A. Buylla y G. Alegre, Jefe de dicha Sección, completamente trascrito en ARÓSTEGUI, Julio - Miseria y conciencia... cit., p. 101-226.

${ }^{53}$ ACOSTA RAMÍREZ, Francisco; CRUZ ARTACHO, Salvador y GONZÁLEZ DE MOLINA, Manuel - Socialismo y democracia en el campo (1880-1930). Los orígenes de la FNTT. Madrid: Ministerio de Medio Ambiente y Medio Rural y Marino, 2009, p. 239-284.

${ }^{54}$ CASTILLO, Santiago - Historia de la UGT. Un sindicalismo consciente, 1873-1914. Madrid: Siglo XXI, 2008, p. 207.

${ }^{55}$ CRUZ ARTACHO, Salvador et alii - El socialismo español y la cuestión agraria (1879-1923). Luces y sombras en el debate teórico y en la práctica sindical y política. Ayer. 54 (2004) 129-163. 


\section{3) 1918-1920: el triunfo de la huelga en la sociedad rural española}

«Los sucesos del verano de 1917 marcaron un hito en el desarrollo de la conflictividad social a todos los niveles... $\rangle^{56}$. Estas palabras hacen referencia a la huelga general ferroviaria de agosto de 1917, considerado por la historiografía como el hecho en el que el movimiento obrero alcanzó su mayoría de edad ${ }^{57}$. La huelga tuvo notable éxito en las grandes ciudades del país y en los principales centros industriales. Y, aunque los sindicatos mayoritarios no consiguieron hacer buenas las reivindicaciones laborales, el movimiento obrero salió reforzado, ya que, por un lado, provocó una crisis de gobierno que con el tiempo fue irreparable para el sistema; $\mathrm{y}$, por otro, a partir de esta fecha, los sindicatos consiguieron captar nuevas masas de obreros, logrando no sólo recuperar, sino superar con creces el nivel de asociaciones y afiliados que tuvieron a principios de siglo ${ }^{58}$.

El campo estuvo mayoritariamente al margen de este importante episodio de la conflictividad social en España, aunque no por mucho tiempo. Al año siguiente, 1918, comenzarán a desarrollarse conflictos laborales campesinos que irán aumentando progresivamente hasta alcanzar su cenit en $1920^{59}$, el año más conflictivo en la España rural hasta la llegada de la coyuntura de la II República.

La importancia del movimiento obrero agrario en estos años fue tal, que los historiadores clásicos consideraron que se aquí se produjo la definitiva integración de los jornaleros y campesinos en el movimiento

${ }^{56}$ ARÓSTEGUI, Julio; GONZÁLEZ CALLEJA, Eduardo y SOUTO KUSTRÍN, Sandra - La violencia política en la España del siglo XX. Cuadernos de Historia Contemporánea. 22 (2002) 53-94. La cita en la p. 68.

${ }^{57}$ La bibliografía sobre la huelga de 1917 es muy profusa, por lo que aquí sólo dejamos constancia de un estado de la cuestión en GÓMEZ OCHOA, Fidel - La crisis de la Restauración (1917-1923) en la historiografía española in RUEDA, Germán (ed.) - Doce estudios de historiografía contemporánea. Santander: Universidad de Cantabria, 1991, p. 183-209.

${ }^{58}$ FORCADELL, Carlos - Conflicto social y movilización obrera: de la huelga general a la dictadura de Primo de Rivera in REDERO SAN ROMÁN, Manuel (coord.) - Sindicalismo y movimientos sociales, siglos XIX y XX. Madrid: UGT; Centro de Estudios Históricos, 1994, p. 99-109.

${ }^{59}$ Véase gráfico 2. 
obrero $^{60}$, conociendo dicho período como trienio bolchevista (o bolchevique), una expresión heredada de Juan Díaz del Moral, autor de Historia de las agitaciones campesinas andaluzas allá por $1928^{61}$, quien consideraba que la acusada agitación social campesina de esos años se debió a la influencia que tuvo el triunfo de la revolución rusa en el proletariado agrario español.

Gráfico 2 - Huelgas agrarias en España, 1905-1929

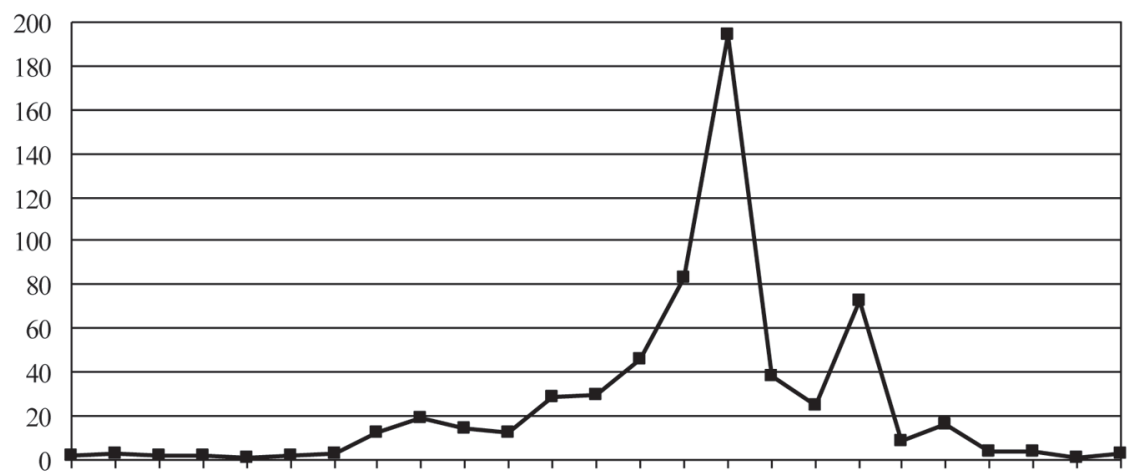

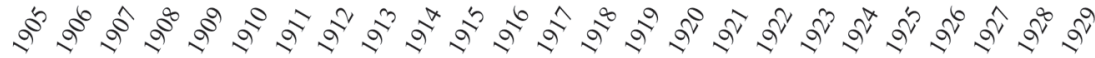

Fuente: Ministerio de Trabajo. Dirección General de Trabajo. Estadísticas de huelgas. Memorias. Años 1905-1929 in ACOSTA RAMÍREZ, Francisco; CRUZ ARTACHO, Salvador y GONZÁLEZ DE MOLINA, Manuel - Socialismo y democracia ... cit., p. 117.

Sin embargo, las investigaciones más solventes han desechado estas explicaciones revolucionarias, y han demostrado que las causas de este nuevo ciclo de conflictividad era una nueva coyuntura económica negativa, a lo cual se unió la aguda crisis política e institucional que sufría el sistema político de la Restauración ${ }^{62}$. La muestra más patente de este hecho es que todos los autores que han estudiado las huelgas agrarias de este período señalan que en ellas apenas hay proclamas revolucionarias, sino que dominan las reivindicaciones laborales, y dentro de ellas, las salariales ${ }^{63}$.

${ }^{60}$ TUÑÓN DE LARA, Manuel - El movimiento obrero en la historia de España. (II). Madrid: Sarpe, 1986.

${ }^{61}$ DÍAZ DEL MORAL, Juan - Historia de las agitaciones campesinas andaluzas. Córdoba (antecedentes para una reforma agraria). Madrid: Alianza, 1973 (1 $1^{\mathrm{a}}$ ed. 1928).

${ }^{62}$ RODRÍGUEZ LABANDEIRA, José - El trabajo rural en España (1876-1936). Barcelona: Anthropos, 1991, p. 259-266.

${ }^{63}$ Como se ha señalado recientemente: «El llamado Trienio Bolchevique, pese a las connotaciones revolucionarias de su denominación, poco tuvo que ver con proyecto articulado 
La neutralidad de España en la I Guerra Mundial produjo notables cambios en la economía nacional. Por un lado se aumentó el número de exportaciones, creando una demanda que en muchas ocasiones superaba la capacidad productiva del país. Por otro, se produjo una disminución de las importaciones por la incapacidad de los países beligerantes y el encarecimiento de los precios del transporte internacional. Este doble proceso se mantuvo hasta 1920, cuando los países beligerantes recuperaron sus respectivos tejidos productivos, obligando a la economía española a centrarse en el abastecimiento del mercado interior. Este hecho produjo la apertura de un proceso inflacionista y un vertiginoso aumento de los precios de los productos de consumo básico, lo cual se dejó sentir con mayor fuerza entre las clases populares del campo ${ }^{64}$.

Gráfico 3 - Índices anuales del precio del pan al por menor (1914-1920)

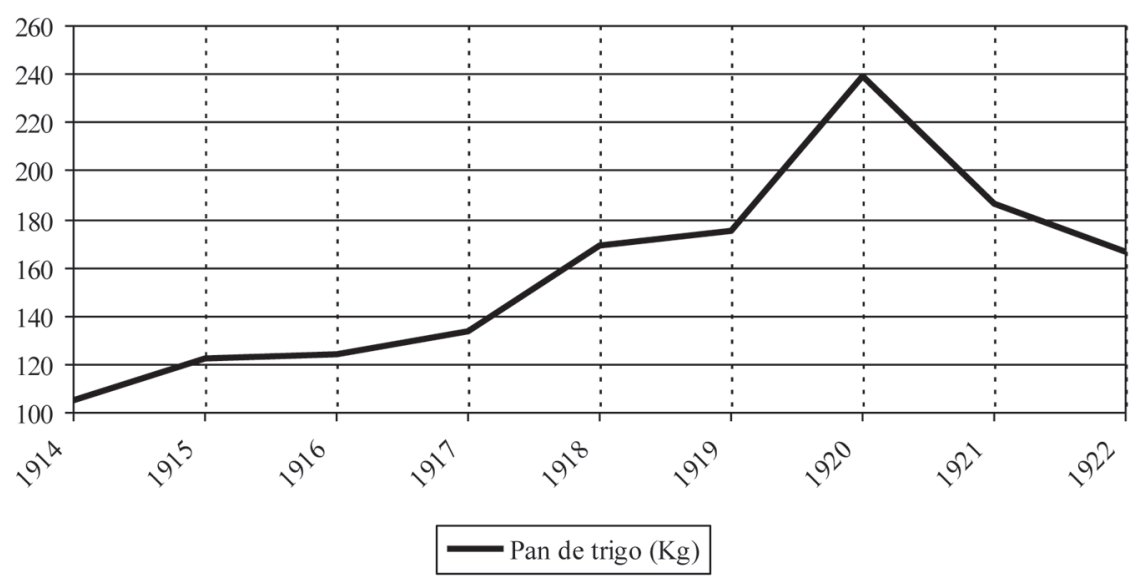

Fuente: ROLDÁN, Santiago y GARCÍA DELGADO, José L. - La formación de la sociedad... cit., p. 138-139.

alguno de transformación social radical, sino más bien con una reactivación del movimiento asociativo agrario en reivindicación de mejores condiciones de trabajo»; en ACOSTA RAMÍREZ, Francisco; CRUZ ARTACHO, Salvador y GONZÁLEZ DE MOLINA, Manuel - Socialismo y democracia... cit., p. 345.

${ }^{64}$ ROLDÁN, Santiago y GARCÍA DELGADO, José L. - La formación de la sociedad capitalista en España, 1914-1920. Vol. I. Madrid: Confederación Española de Cajas de Ahorro, 1973. 
Durante largo tiempo este movimiento obrero agrícola se creyó, erróneamente, limitado a Andalucía ${ }^{65}$. Todo lo contrario. En el caso de Castilla y León, por ejemplo, las estadísticas gubernamentales señalan que también acogió el mayor número de conflictos durante esos mismos años ${ }^{66}$.

Aún con todo, cabe señalar que las estadísticas nacionales no reflejan la verdadera dimensión de la protesta campesina de 1918-20. A. Calero Amor advierte que estudios regionales y locales recogen entre cinco y doce veces más conflictos que los señalados por las estadísticas del Instituto de Reformas Sociales (IRS) y cuatro veces más que los noticiados en El Socialista (el periódico oficial del Partido Socialista Obrero Español) ${ }^{67}$.

Retomando el ejemplo de Castilla y León, y en concreto el de la comarca triguera de Tierra de Campos, al manejar documentación judicial y militar y la prensa provincial, vemos que la conflictividad social tuvo mucho mayor calado en la región de lo que reflejan los documentos gubernamentales. Así, mientras C. Hermida Revillas constata para pueblos de Tierra de Campos un total de 26 huelgas agrícolas entre los años 1917-23, nuestros estudios han elevado ese número a $96^{68}$.

A lo largo de la última década, otras investigaciones regionales que se han dedicado al análisis de la protesta campesina, muestran como distintas regiones españolas con diversas características socio-económicas (Badajoz ${ }^{69}$, La Rioja ${ }^{70}$, Castilla-La Mancha ${ }^{71}$ o Aragón ${ }^{72}$ ) también acogieron la mayor cantidad de huelgas agrarias durante la coyuntura de 1918-20.

Queda patente, por tanto, que la crisis socio-económica posbélica supuso una notable expansión del movimiento obrero en el campo español, donde,

${ }^{65}$ MAURICE, Jaques - A propósito del trienio bolchevique in GARCÍA DELGADO, José L. - La crisis de la Restauración ... cit., p. 337-350; DELGADO LARIOS, Almudena - ¿Problema agrario o cuestión nacional? El mito del Trienio Bolchevique en Andalucía (1918-1920). Cuadernos de Historia Contemporánea. 13 (1991) 97-124.

${ }^{66}$ HERMIDA REVILLAS, Carlos - Economía agraria y agitaciones campesinas en Castilla la Vieja y León: 1900-1936. Madrid: Universidad Complutense de Madrid, 1989, p. 137-146.

${ }^{67}$ CALERO AMOR, Antonio M. - Movimientos sociales... cit., p. 49.

${ }^{68}$ Véase REDONDO CARDEÑOSO, Jesús-Ángel - Protesta y violencia... cit., p. 64-82.

${ }^{69}$ BAUMEISTER, Martin - Campesinos sin tierra ... cit., p. 361-368.

${ }^{70}$ GIL ANDRÉS, Carlos - Echarse a la calle... cit., p. 136-157.

${ }^{71}$ BASCUÑÁN AÑOVER, Óscar - Protesta y supervivencia ... cit., p. 123-151.

${ }^{72}$ LUCEA AYALA, Víctor - El pueblo en movimiento... cit., p. 418-430. 
a igual que ocurrió en el resto de España, «la huelga se convirtió en el mecanismo de movilización más utilizado» ${ }^{73}$.

No obstante, de nuevo tenemos que señalar que el avance de la huelga como principal expresión de protesta colectiva del campesinado español no supuso el abandono de viejas prácticas de acción popular como eran los motines. En este sentido, durante la primavera y los inicios del verano de 1920, coincidiendo con los días en que los precios de las subsistencias alcanzaron sus máximos costos, se extendieron numerosos motines en donde la multitud reclamaba a las autoridades medidas para rebajar los artículos de primera necesidad en regiones como La Rioja ${ }^{74}$, las provincias de Toledo y Ciudad Real ${ }^{75}$, y Badajoz ${ }^{76}$.

\section{A modo de conclusión}

Si durante largo tiempo el estudio de la conflictividad social en el campo español estuvo restringido a una región como Andalucía y vinculada a la influencia que tuvo el anarquismo sobre los jornaleros de los latifundios del valle del Guadalquivir, desde los últimos años del pasado siglo hasta hoy día se han venido realizando numerosas investigaciones que han dado un vuelco a la tradicional concepción historiográfica que caracterizaba a la sociedad rural como una laguna de paz social en medio de la convulsa España de principios de siglo XX.

El campo español fue un continuo foco de latente conflicto social durante todos aquellos años, estallando en determinadas coyunturas (1898, 1903-04 y 1918-20) como consecuencia de la extensión de diversas crisis de subsistencias. En estas coyunturas el campesino no sólo acudió a la ejecución de motines y alborotos populares, los cuales habían sido la expresión de protesta colectiva tradicionalmente utilizada por las masas populares desde el Antiguo Régimen, sino que también se mostró abierto a

${ }^{73}$ CRUZ MARTÍNEZ, Rafael - Crisis del Estado y acción colectiva en el período de entreguerras (1917-1939). Historia Social. 15 (1993) 119-36. Cita en p. 129.

${ }^{74}$ GIL ANDRÉS, Carlos - Echarse a la calle... cit., p. 134-135.

${ }^{75}$ BASCUÑÁN AÑOVER, Óscar - Protesta y supervivencia ... cit., p. 141.

${ }^{76}$ BAUMEISTER, Martin - Campesinos sin tierra ... cit., p. 288-300. 
